\title{
0 problema da coesão na sociedade comercial
}

Tradução: Julia Marchevsky

\section{Christopher J. Berry}

University of Glasgow

O título deste ensaio é extraído da obra de John Brown An Estimate of the Manners and Principles of the Times (I757). Como parte de uma crítica veemente à sociedade de sua época, Brown enuncia que "o elo do interesse próprio (self-interest) é tão forte quanto uma corda de areia, não há cimento entre as partes, não há coesão entre elas” (Brown, I757, II.4.III). Essa crítica não foi endossada por nenhum dos autores ligados ao chamado Iluminismo Escocês, embora alguns deles tenham, eventualmente, formulado uma ideia similar. Lorde Kames, por exemplo, em algumas passagens de Sketches on the History of Man (1774), exibe sentimentos próximos ao de Brown, especialmente na seção Sketch on Patriotism. Outros, mais sofisticados, mobilizaram a essência implícita no argumento de Brown, como Adam Ferguson, que nas seçôes finais do Ensaio sobre a história da sociedade civil ( 1767 ) desfere um ataque à passividade e ao atomismo da sociedade contemporânea ou comercial. ${ }^{1}$ Tanto Kames quanto Ferguson, no entanto, distanciam-se da visão endossada por Brown, e reconhecem a superioridade da sociedade comercial em relação às demais. Admitem que o interesse próprio é imprescindível a uma sociedade onde, nas palavras de Smith, “todo homem é, em alguma medida, um comerciante" (WN, p. 37). E, por essa razão, rejeitam o argumento de Brown, sustentando que a sociedade comercial exibe ou estabelece alguns princípios de coesão que são, de fato, mais robustos que uma "corda de areia" (a rope of sand).

Embora nenhum dentre os escoceses tenha argumentado diretamente contra Brown, procurarei mostrar no que se segue como terminam por responder às objeçóes

\footnotetext{
1 [N. T.] Cf. tradução recém-publicada pela Editora Unesp: Ferguson, Ensaio sobre a história da sociedade civil. Trad. Pedro Paulo Pimenta e Eveline Campos Hauck. Sáo Paulo: Editora Unesp, 2019.
} 
à ideia de sociedade comercial feitas por esse polemista. ${ }^{2} \mathrm{O}$ foco de minha exposição é Adam Smith, embora eu me refira também, eventualmente, a outros autores.

I

Começarei por uma contextualizaçáo geral. Para sustentar com êxito a ideia de coesão na sociedade comercial, os escoceses têm de se haver com Hobbes e reconciliar as noçóes de interesse próprio e de coesão social. Como se sabe, para Hobbes, cada ser humano se interessa por seu próprio bem-estar em detrimento daquele dos demais. Smith admite que os seres humanos buscam prazer e evitam a dor. Mas rejeita a noção hobbesiana de que os outros indivíduos são sempre rivais efetivos ou em potencial. Com efeito, para Hobbes, a soluçáo para essa competição desenfreada por recursos e glória é o estabelecimento de um soberano autorizado (authorised sovereign), dotado do poder de impor definiçôes inequívocas de bem e mal. Essa imposição seria necessária, pois, como aponta Hobbes, "sem a espada, tratados são meras palavras", e os indivíduos precisam ser "aterrorizados" por um poder soberano para que possam "agir como lhes cabe" (Hobbes, I99I, pp. 38-39, 92, II7).

Autores contemporâneos a Hobbes e posteriores a ele concluíram disso que a moralidade não passaria da resignação aos éditos do soberano, por meio de coerção. Enquanto muitos de seus críticos, como Samuel Clark, optaram por um viés racionalista, outros, como Shaftesbury, atribuíram as doutrinas de Hobbes a uma concepção equivocada de natureza humana. Segundo Shaftesbury, os indivíduos, longe de serem irredutível ou exclusivamente autocentrados, possuem um "senso moral natural" que os inclina a promover o bem da espécie. ${ }^{3}$

Essa ideia foi recuperada pelos escoceses, embora a influência de Shaftesbury tenha sido mediada pelo impacto de Mandeville. Como Hobbes, embora de maneira mais insidiosa, Mandeville alegava que açóes virtuosas não necessariamente produziam resultados benéficos, como poderiam ter os mesmos efeitos de açôes viciosas; e, ao contrário, o que se toma por vício poderia produzir a virtude. Por exemplo,

2 Em sua correspondência, Hume menospreza Brown ao apontá-lo como um bajulador do "baixo sujeito Warburton" ("low fellow Warburton") e dizer que ficaria "certamente constrangido por debatê-lo" (Hume, I932, I, 250 [n. I32]). Robert Wallace foi o único escocês que discutiu as ideias de Brown (Wallace, I768, especialmente capítulo 5). Apesar de suas hesitações quanto à sociedade comercial, Wallace faz uma crítica demasiada extensa ao livro de Brown. Brown, por sua vez, menciona os ensaios de Hume em apenas uma situaçáo ao referir-se à queda da influência do clero (cf. "Whether the British Government inclines more to Absolute Monarchy or to a Republic", I74I). O único contemporâneo a quem Brown se refere é Montesquieu, embora mencione algumas vezes Davenant no que tange ao tema do comércio (trade) e desaprove a recepção apática dada a Bolingbroke. A obra An Estimate of the Manners and Principles of the Times, embora tenha sido popular, não continha muita erudição (scholarship), sendo raras as referências aos moralistas e aos historiadores romanos.

3 Shaftesbury, I990, I, 262. Ele acusa Hobbes de "alterar" (shifting) termos para "explicar todas paixôes sociais e afeiçóes naturais como se fossem egoístas” (Op. cit, p. 79). 
o orgulho e o luxo (principais alvos de Brown) estimulam, segundo Mandeville, a indústria (Mandeville, I998, I, p. 86). Seus contemporâneos atribuíram a Mandeville a ideia que a virtude era uma ficção, e de que todos aqueles considerados virtuosos (isto é, corretos) por si próprios eram hipócritas. Ainda mais grave, porém, era a alegação de Mandeville de que a teoria de Shaftesbury estaria incorreta por ser "inconsistente com a nossa experiência cotidiana" (Ibid., p. 324). Dentre os críticos de Mandeville, destacou-se Francis Hutcheson, que sustentou que o autor da Fábula das abelhas não compreendera adequadamente a experiência humana em sociedade.

Encontramos o eco dessa crítica logo no início da Teoria dos Sentimentos Morais: "Não importa quão egoísta supomos que seja o homem, há, evidentemente, em sua natureza, princípios que o levam a se interessar pela sorte dos outros, e que tornam a felicidade deles necessária à sua, embora nada ganhe com isso além do prazer de contemplá-la” (TMS, I.i.I., p. 9). ${ }^{4}$ Mas Smith nada diz acerca da natureza desses princípios. Enquanto Hutcheson julga que o amor-próprio pressupóe conduta moral ou é uma subcategoria da benevolência ${ }^{5}$, aos olhos de Smith (e de Hume) isso não é suficiente para, de um lado, responder ao desafio de Brown, e, de outro, rechaçar a posição de Hobbes e Mandeville. Para tanto, são necessários argumentos ulteriores.

\section{II}

Adam Smith afirma explicitamente que, não importa se a sociedade é comercial ou não, cada indivíduo tem sempre uma "preferência natural [...] por sua própria felicidade, em detrimento da dos outros" (TMS, II.ii.2.I, p. 82). Embora seja um fato, tal preferência não se dá isoladamente, pois o efeito da sociabilidade precisa ser levado em consideração. Tanto Smith (TMS, III.i.3, p. III) quanto Hume (I987a, p. 365) associam a imagem da sociedade a um espelho no qual são refletidos, para nossa contemplação, os efeitos de nossas ações. Para Smith, é uma fraqueza da visão hobbesiana/mandevilliana não considerar o fato de que as interaçôes da vida social "despertam humildade, em meio à arrogância do amor-próprio" (TMS, II.ii.2.I, p. 83). Essa humildade socialmente induzida restringe o egoísmo e dá ensejo às afeições benevolentes (TMS, I.i.5.5, p. 25).

Isso ocorre de maneira mais efetiva nas sociedades comerciais e modernas, isto é, naquelas que constituem o principal alvo das críticas de Brown. O cerne da teoria moral de Smith é a simpatia: o uso da imaginação de cada um, que se projeta num

\footnotetext{
4 Compare com a frase de abertura de Hutcheson da obra Inquiry into Virtue and Moral Goodness (I725), "a bondade moral denota nossa ideia de alguma qualidade apreendida em açóes, as quais buscam aprovação acompanhada pelo desejo de felicidade do agente" (Hutcheson, I994, p. 67).

5 Hutcheson, I994, pp. 86-95.
} 
espectador imparcial e avalia de forma reflexiva a adequação de certo comportamento dentro de um contexto. Essa avaliação por meio da simpatia não é automática nem fixa. Uma variável importante é a proximidade emocional. Em um ambiente mais tolerante, como o de familiares e amigos, a concordância pela simpatia é mais facilmente obtida do que em relações de mercado conformadas entre indivíduos relativamente anônimos, espaço que requer esforço maior para alcançar o estado desejado de harmonia entre ator e espectador (cf. TMS, I.i.4.Io, p. 23). Essa dificuldade produz o fortalecimento do caráter dos indivíduos. Em outras palavras, o ator em uma sociedade comercial exerce um grau maior de moderação e manifesta a virtude do autodomínio (self-comand) de modo mais consistente do que em clás ou tribos (cf. TMS, III.3.25, p. I46). Um comportamento irresponsável e displicente tem mais chances de ser perdoado ou tolerado entre amigos e familiares do que por uma instituição "impessoal", como um banco, por exemplo. Interagir entre estranhos, portanto, promove certa disciplina.

Apesar do interesse individual que as anima, as sociedades modernas apresentam outras virtudes que as tornam superiores a outras. Um "povo refinado" (polished people), segundo Smith, adquire hábitos que o torna "franco, tolerante e sincero" (TMS, V.2.II, p. 208). Em suas aulas na Universidade de Glasgow, Smith observou que "quando a maior parte da população é composta por mercadores, estes incorporam aos costumes a probidade e a pontualidade", qualidades que se convertem "[n]as principais virtudes de uma nação comercial” (Smith, I982, p. 539). Dizer que elas são as principais virtudes equivale a dizer que estáo consolidadas. Como mentiras e atrasos são atitudes reprováveis e como todos buscam aprovação na psicologia moral e social de Smith, a ação dos indivíduos será conforme o que denominamos de "normas comerciais". Dado que a "opinião favorável" ("good opinion”) dos outros é sempre desejável, um "grau considerável de virtude" e uma "conduta regular", segundo Smith, serão produzidos como resultados delas (TMS, I.iii.3.4, p. 63).

Essa conduta, principalmente na forma de adesão às regras de justiça, é parte integral da sociedade moderna. Para Smith, a "recompensa" por agir de maneira justa e ser honesto é a confiança depositada em nós pelas pessoas com as quais convivemos (TMS, III.5.8, p. I66). Como enfatizaremos mais adiante, a credibilidade e

\footnotetext{
${ }^{6}$ Smith não está sozinho. Por exemplo, John Millar afirma que "os indivíduos formam suas noções de propriedade de acordo com um padráo geral, e moldam sua moral em conformidade com o gosto prevalecente na época" e, na mesma passagem, associa isso à presença de "um espírito mercantil [que] não é restrito apenas a mercadores ou comerciantes; ele permeia em algum grau todas as ordens e as posiçóes sociais [orders and ranks] pela similaridade da situaçáo e atinge, em uma medida maior ou menor, todos os membros da comunidade devido à influência do hábito e do exemplo" (Millar, 2000, p. 777). Ver também Ferguson, 1966, p. I89. Ferguson refere-se à "pontualidade e [à] negociação justa" como o "sistema de costumes" ("system of manners") dos mercadores.
} 
a confiança, ao mesmo tempo que promovem coesão, são cruciais para o estabelecimento de um "bom governo" e dos comportamentos necessários ao bom funcionamento de uma sociedade comercial.

\section{III}

Seriam tais requisitos mais fortes que uma "corda de areia"? $\mathrm{Na}$ tentativa de uma resposta inicial, farei uma adaptação do famoso exemplo de Smith acerca de uma transação comercial: açougueiros e seus clientes. Estes últimos oferecem dinheiro em troca de carne, sem apelar - no curso normal dos eventos (in the normal course of events) — à benevolência ou à humanidade dos primeiros, mas sim ao "amorpróprio", nas palavras de Smith, dos açougueiros (WN, I.ii, p. 27). Isso não significa que uma açougueira não é capaz de ser benevolente, ela até pode oferecer algumas linguiças a um pedinte, mas isso depende de sua vontade, diferentemente da venda de alimentos por um montante de dinheiro adequado. Caso vendesse dez linguiças pelo preço de doze, tal açougueira adquiriria uma má-reputação, o que a faria perder futuros negócios. Logo, é seu interesse próprio que promove a moralidade das trocas justas. De maneira similar, para o cliente é vantajoso ter a reputação de bom pagador. Afinal, bancos não emprestarão para alguém com registro de inadimplência, pois ganham a partir dos juros sobre os empréstimos, enquanto o cliente adquire fundos para expandir seus negócios ou até mesmo sair de férias.

A fim de melhor explorar o sentido dessa reciprocidade na constituição da coesão social, podemos identificar, de forma simplificada e algo abstrata, três maneiras pelas quais, suponhamos, Adão pode conseguir algo por ele almejado que está sob a posse de Eva. Na primeira suposição, Adão simplesmente retira o objeto desejado de Eva. Se esse fosse a forma padrão das interaçóes de trocas entre os indivíduos, estaríamos subscrevendo o modelo de Hobbes, no qual a competição, a falta de confiança (o que Hobbes denomina de "diffidence") e a necessidade de ser superior leva à ausência de "indústria" (industry) e à existência de uma vida curta e brutalmente miserável (Hobbes, I99I, capítulo I3). Por ser essa a "condição natural da humanidade", Eva é igualmente motivada a tomar o objeto desejado de volta. Mesmo com a implementação da única solução enxergada por Hobbes, a instabilidade social não é removida, pois o que previne Adáo de simplesmente apanhar o que ele deseja é o medo de punição por parte do soberano - o sujeito artificial (Leviatã) criado pelo acordo mútuo entre Adão, Eva e todos os demais. Mas Smith e outros escoceses rejeitavam tal concepção por estar fundada em uma leitura equivocada da natureza humana (em breve retornarei ao tema da "natureza humana"). A sociedade não tem sua coesão mantida por meio do medo. Hume alega que todos governos estão fundados na "opiniáo", explicitando o medo como um princípio secundário, embora 
com alguma importância7. Já Smith avalia que, em contraste com a "administração e a persuasão", a "força e a violência" são os piores instrumentos para governar (WN, V.i.g, p. 799). A sociedade hobbesiana está sempre exposta à instabilidade ou à falta de coesão. Uma ordem social que é imposta sem mais permanece vulnerável à dissolução interna, devido ao exercício do direito natural de autopreservação.

$\mathrm{Na}$ segunda suposição, Adão recebe o que deseja ou necessita como um presente de Eva. Um ato de benevolência pode ser, nesse sentido, um "bom negócio". De forma equivalente, doar para a caridade é, no nível da vida diária ou no curso irrefletido da vida comum, uma ação moralmente boa. A caridade cristã ou a prática benevolente de dar presentes parece ser o modelo das próprias prescriçôes de Brown. Entretanto, elas também são instáveis, e podem ser vistas como uma "corda" que não consegue fornecer grande sustentação por causa de um elemento discricionário; ou, na linguagem jurisprudencial da época de Smith, a benevolência é uma obrigação imperfeita, pois não pode ser externamente compelida. Mesmo que concordemos com Brown acerca da obrigaçáo de ser benevolente ou do cumprimento dos deveres cristãos, a benevolência não tem uma força suficientemente coesiva em uma sociedade comercial.

Apesar de todos os males acoplados à sociedade comercial por Brown, o ponto de vista smithiano não sustenta que indivíduos não podem (ou não devam) agir "moralmente" nem seguir sua consciência, apenas que essa "ação" não pode ser generalizada enquanto princípio fundacional da sociabilidade. Como é enfatizado por Smith, a sociedade pode existir sem beneficência, mas não sem justiça (TMS, II.ii.3.3, p. $86)^{8}$. Consequentemente, a sociedade browniana, se baseada somente na beneficência, dificilmente terá coesão. Somente a justiça poderia funcionar como um cimento (para utilizar outra imagem de Brown), pois não é discricionária nem arbitrária. Enquanto todos podem concordar que atos injustos devem ser punidos, não há acordo sobre quem merece beneficência. Por isso Hume critica a "moralidade natural", pois ela tem o potencial de exacerbar discordâncias sociais ser maior do que o de resolvê-las (Hume, I987a, p. 489), e Smith faz objeçóes às formas de justiça que vão além de seu entendimento mais restrito da mesma (TMS, VII.ii.9, p. 269).

$\mathrm{Na}$ terceira suposição, Adão e Eva realizam um escambo ou transação. Suponhamos que Adão tenha duas facas e nenhum garfo, Eva tenha dois garfos e nenhuma faca e ambos desejam ter uma faca e um garfo. Seguindo seus interesses próprios, eles podem efetuar uma troca de forma a satisfazer seus respectivos desejos.

\footnotetext{
7 "Of the First Principles of Government". In: Hume, 1987b, pp. 33-34.

8 Para uma discussão de Smith sobre beneficência ver Hanley, 2009, pp. 178-187. Hanley chega a atribuir "primazia" à beneficência (Ibid., p. I79), mas essa parece ser uma afirmação indevida.
} 
Essa transação não depende de Adão e Eva se conhecerem reciprocamente. Ocorre nas circunstâncias prevalecentes na sociedade comercial ou no que Smith denomina de "assembleia de estranhos" (TMS, Ii.4.9, p. 23). Ela está fundada na força previsível do interesse próprio. Diferentemente do primeiro modo de transação, não depende da ameaça de sanção para prevenir que Adão simplesmente pegue um dos garfos de Eva. E, distinta da segunda forma de troca, não depende de discrição: Eva poderia presentear Adão com um de seus garfos, mesmo que ele tivesse inicialmente apenas uma faca, assim como ela também poderia não o fazer. Entretanto, se Adáo tem algo que Eva gostaria de receber em troca, então ambos têm um motivo para fazer negócios. É essa mutualidade que, em uma escala maior, provê o cimento para a coesão social se firmar.

Contudo, a visão browniana ainda poderia criticar o modelo de trocas por também ser fruto de contingências. Como a motivação está fundada no interesse próprio, se uma parte não tiver o que fornecer em troca, a transação não ocorrerá e tal possibilidade compromete esse modelo de coesão. Assim, a corda de areia ainda permanece.

\section{IV}

Qual a resposta smithiana para essa objeção? Um caminho é a reafirmação de que o interesse próprio não é um princípio que exclua os demais. Os seres humanos atuam com base em outros princípios, que dão suporte à coesão. Todavia, quero deixar essa resposta momentaneamente de lado, a fim de enfrentar a objeçáo específica contra a sociedade comercial. Para tanto, é preciso examinar suas implicaçóes. A sociedade em que "todo homem é, em alguma medida, mercador", é uma sociedade de interdependência; e esta é consequência necessária da divisão do trabalho. A extensáo da divisáo do trabalho (e, logo, da riqueza da sociedade) depende da extensão do mercado, a qual, por sua vez, depende da confiança no futuro.

Em suma, Adão produzirá facas para vendê-las, enquanto Eva fará garfos também para vendê-los, mas eles irão optar por se especializar dessa forma apenas se estiverem confiantes de que, no futuro, poderão realizar suas respectivas vendas. Do contrário, os interesses próprios de Adão e de Eva os levariam a produzir facas e garfos. Todavia, nesse caso haveria a produção de uma quantidade menor de talheres no total, pois o esforço individual estaria disperso entre diferentes tarefas. Ademais, as manufaturas produzidas seriam de qualidade inferior do que aquelas feitas com um grau maior de especializaçáo. Essa interdependência, em uma escala maior, é a sociedade comercial. E é essa sociedade que suprime "a pobreza miserável" e aprimora o bem-estar de todos — cada pessoa desfruta de melhores alimentos, vestimentas e habitaçóes do que em qualquer outra sociedade que levasse a sério as 
prescriçốes de Brown (ou mesmo, diga-se de passagem as de Rousseau) ${ }^{9}$. Junto de uma maior riqueza social, as virtudes de caridade e de benevolência são praticadas mais efetivamente em "naçóes prósperas e civilizadas" (WN, Introd. 4, p. IO). Se essas virtudes fossem vistas por Brown como indutoras de coesão, logo, a sociedade comercial, nesses mesmos termos, também seria coesa.

A sociedade moderna, baseada na confiança, precisa de algum suporte institucional. Este aparece na forma do primado do direito (rule of law), o qual tem o efeito de prover a segurança e a previsibilidade requeridas pela sociedade comercial. Sem elas, a divisão do trabalho e o estabelecimento do mercado não seriam viáveis. Esse argumento é crucial n'A Riqueza das Naçôes. Mas, mesmo que a coerção seja necessária, não se trata com isso de voltar a Hobbes, para quem todos tentam se beneficiar ao máximo em detrimento dos demais, pois o resultado das interaçóes é soma-zero. Ora, a vantagem decisiva de uma sociedade fundamentada na troca é sua característica de não ser uma soma-zero (tanto Adão quanto Eva recebem garfos e facas).

Por que as pessoas em uma sociedade comercial não tentam tirar vantagem (freeride $\left.{ }^{10}\right)$ dos demais? Por causa dos efeitos de apoio mútuo conferidos pela confiança. É o cerne da coesão das sociedades modernas, e a razão de por que elas são sustentadas por algo mais forte que uma "corda de areia".

Tanto para Smith quanto para Hume, a justiça é essencial. Embora tenha, no caso de Smith, uma origem "natural” no ressentimento, ela ainda é um produto da experiência: nós aprendemos a ser justos. As regras de justiça são ensinadas por meio de "disciplina, educação e exemplo" (TMS, III.5.I, p. I63). Ao ser exposto a esse grau de instrução - correspondente ao próprio processo de sociabilização - um indivíduo, quase sem exceção, pode desfrutar de uma vida decente e, na prática, isenta de culpa. A convivência em sociedade não requer qualidades sobre-humanas características de santos ou heróis. O que permite aos indivíduos conviverem de maneira minimamente pacífica é o fato de compartilharem, por meio dessa instrução comum, de certo senso de justiça. Esse acordo "sentimental” provê confiança e convicção suficientes para poder contar com a conduta dos demais (Ibid.).

Podemos acrescentar que a perspectiva de Smith (similar à de Hume) é compatível com algumas análises contemporâneas. Por exemplo, segundo Elionor Ostrom, os seres humanos, à medida que aprendem a confiar uns nos outros, desenvolvem

\footnotetext{
9 Ver Berry, 2013, cap. 3.

${ }^{10}$ [N. T.] Free-ride, algumas vezes traduzidos como o comportamento de pegar caronas, é um termo bastante presente na literatura econômica, principalmente na área de gestão de recursos comuns, a qual pertence Elionor Ostrom mencionada por Berry dois parágrafos adiante. Em linhas gerais, o termo refere-se ao comportamento de tentar tirar vantagem de certa situaçáo em detrimento dos demais, como pescar mais peixes que a cota permitida em um rio.
} 
normas de reciprocidade. Ostrom chama atenção para o "fato" de que quando muitos indivíduos agem de modo recíproco, há incentivos para a obtenção de uma reputação de manter promessas e realizar açóes com custos de curto prazo e benefícios de longo prazo (Ostrom, 1998, p. I2). Entáo, mesmo os que buscam tirar vantagens dos demais (free-riders), como o "canalha sensato" (sensible knave) de Hume, sofrerão "uma perda completa de reputação, e de toda futura confiança e fiabilidade por parte da humanidade" (Hume, I998, p. 156). Smith acrescentaria que essa perda seria, mesmo para o "canalha", dolorosa, pois todos seres humanos têm uma "aversão originária" ao ato de ofender os outros (TMS, III.2.6, p. II6).

A aversão e a confiança interpessoal socialmente induzida, identificadas por Smith, precisam ser institucionalmente reforçadas, como foi mencionado. É vivendo sobre o primado do direito que indivíduos terão "confiança” na "fé dos contratos" e no "pagamento de dívidas" (WN, V.iii.7, p. 9I0). Apenas em "países comerciais", segundo a Teoria dos Sentimentos Morais, "a autoridade da lei [...] é suficiente para proteger, por si mesma, o mais insignificante homem dentro do Estado" (TMS, Vi.ii.I.I3, p. 223). A grande vantagem dos tempos modernos, conforme explica Smith em suas aulas de retórica, é o aumento da segurança decorrente da separação entre justiça e política (Smith, I983, p. I76). Mais uma vez, a "modernidade" é crucial. É com a introduçâo do "comércio e das manufaturas" que "a ordem, o bom governo e, junto deles, a liberdade e a segurança dos indivíduos" são encontrados, situação que contrasta com as guerras e a "dependência servil" a superiores características de sociedades pré-comerciais (WN, III.iv.4, p. 4I2).

Brown ataca tais sociedades pelo enervamento e pela efeminação dos indivíduos, vícios que, provocados pelo luxo, levariam, entre outras coisas, ao comprometimento da capacidade militar, a sociedade comercial é, sim, forte ${ }^{11}$. Mas, como argumenta Hume no ensaio "Do refinamento das artes", as épocas de refinamento (isto é, de luxo) promovem a indústria, o conhecimento e a humanidade, um trio indissolúvel, que não se afirma em detrimento da virtude marcial (Hume, 1987b, p. 268-280). Para Smith, exércitos profissionais são superiores às milícias compostas por cidadãos (WN, V.I.a.22, p. 699). Ademais, qualquer tentativa de introduzir tais milícias seria contrária às inclinaçóes dominantes da população em sociedades modernas e, inclusive, pouco palatável, dada a necessidade de uma "administração muito rigorosa" (very rigorous police) para reforçar a participaçáo nelas (WN, V.i.a.I78, p. 698 e cf. V.i.f.59, p. 787). Em suma, isso implica uma sociedade em que cada homem vive

\footnotetext{
${ }^{11}$ Por exemplo, ele atribui o pânico causado pela incursão jacobina na Inglaterra ao fato de que "o espírito covarde da efeminaçáo se instaurou sobre nós, destruindo o espírito nacional da defesa” (Brown, I757, II.3, p. 9I)
} 
por meio da troca e age com base no interesse próprio, mais pacífica, mais equânime e, sobre esses fundamentos sólidos, mais coesa do que Brown alega.

Mas, outros problemas poderiam ainda ser apontados, como o de saber em que medida as operaçóes da sociedade comercial minam a sua própria integridade e, por extensão, sua coesão. Deixando-se de lado o crescimento da desigualdade material por ser um tema que não desperta o interesse de Smith nem Brown, essa corrosão poderia ser identificada no comprometimento das "virtudes intelectuais, sociais e marciais" dos "trabalhadores pobres" (WN, V.i.f.50, p. 782) ou na corrupção dos sentimentos oriundos da disposição por admirar os ricos e privilegiar o status em detrimento da soberania e da virtude (TMS, I.iii.3.I, p. 6I-62). Entretanto, esses problemas talvez sejam apenas efeitos colaterais para os quais Smith já fornece certos remédios (Berry, 20I3, cap. 7). Mesmo assim, restam ainda duas outras possíveis críticas dentro da perspectiva browniana.

\section{V}

Primeiramente, a fundamentação da sociedade comercial não reside em nada mais tangível que a confiança - junto de suas crenças associadas, sua opiniáo, sua expectativa e seu "crédito" —, o que parece ser pouco substancial para sustentar uma ordem coesa. A principal preocupação era a confiança estar, em vez de ancorada, flutuando no mar da incerteza; era a sociedade comercial ser líquida e não sólida. Para Brown e outros de seus contemporâneos, como Davenant e Bolingbroke - que estão entre os poucos autores reconhecidos por Brown —, o mundo do intangível permite o florescimento de especuladores e de agentes no mercado de açóes ("stockjobbers"). Ademais, o caráter abstrato e dependente de crenças das sociedades comerciais torna esse perigo ainda mais insidioso. Como a incerteza e o risco são intrínsecos ao comércio (Adão pode não conseguir vender suas facas), não há garantias. Por essa razão, a coesão social talvez não seja, de fato, mais forte que uma corda de areia.

Smith, menos otimista que James Steuart ou Robert Wallace, reconhece os perigos do crédito. Apesar de certa resignação em seu tom, não há - deixando-se de lado frases ímpares - evidências que tais perigos seriam avaliados como um golpe fatal. Todavia, nesses termos ainda não fica claro o porquê de a sociedade browniana não ser mais coesa. A crença em um superintendente providencial não é mais substancial - e igualmente propensa à presença de extremos — que a crença da ação humana ser, no geral, previsível. Do mesmo modo, o respaldo institucional de uma igreja estabelecida náo provê mais cimento que o respaldo institucional do direito.

Nesse ponto, entretanto, reside a segunda crítica da perspectiva browniana. $\mathrm{Na}$ Teoria dos Sentimentos Morais, ao enfatizar o caráter imprescindível da justiça, Smith menciona o exemplo de uma sociedade de mercadores (TMS, II.ii.3.2, p. 86). 
Embora pudesse estar apenas se referindo aqui às relaçóes internas de troca, Smith define a sociedade comercial como uma sociedade em que cada indivíduo é um mercador em algum grau, logo a referência mais ampla é justificada. Ele escolhe esse exemplo com o objetivo de identificar a sociedade na qual "o amor mútuo e a afeição" estão ausentes. Esses sentimentos não são essenciais, pois compradores e vendedores, interagindo enquanto indivíduos interessados em si próprios com o propósito delimitado de trocar, podem coexistir sem ter nenhuma espécie de ligação emocional entre si. Mas a questão browniana permanece: essa falta de ligação não corroeria a coesão social?

Smith não é indiferente ao tema. Inclusive, na mesma passagem, ele reconhece que uma sociedade sem amor não é muito atraente; e, no parágrafo imediatamente seguinte, alega que a sociedade "floresce" quando seus membros estão "unidos pelos elos agradáveis do amor e da afeição" (TMS, II.ii.3.I, p. 85) ${ }^{12}$. Por trás dessa afirmação, está o contexto que os seres humanos não são autossuficientes. Mas, como foi visto anteriormente, a beneficência náo provê um suporte suficientemente sólido para uma sociedade extensa. A mesma qualificação é aplicável a outra afirmação de Smith, segundo a qual é da natureza dos seres humanos "amar" seu "próprio país" ao ponto de o julgarem superior aos demais, mesmo que estes sejam "da mesma espécie” (TMS, VI.ii.2-4, p. 227-229). Mas a ênfase de Smith no amor pátrio não corresponde a um desvio radical do argumento até agora desenvolvido:

Quem não está disposto a respeitar as leis e a obedecer ao magistrado civil não é um cidadão; e certamente não é um bom cidadão, se não deseja promover [...] o bem-estar da sociedade como um todo e de seus concidadáos. Em épocas pacíficas e tranquilas, esses dois princípios coincidem, $[\ldots]$ e o apoio ao governo instituído parece ser, evidentemente, o melhor expediente para manter a segurança, o respeito e a felicidade que prevalecem entre seus concidadáos (TMS, V.iii.2.II-I2, p. 23I).

Esses "tempos tranquilos" costumam ser frutos da sociedade comercial. Portanto, nas circunstâncias da sociedade comercial — que são as relevantes para o problema aqui tratado - , agir justamente e cumprir as leis propiciam bem-estar social de um modo mais amplo.

Contudo, um browniano poderia avaliar que o peso crucial de manter as regras e agir conforme a justiça significa que a "corda" permanece frágil, e não propicia a coesão necessária. A primazia dada à justiça por Smith e Hume revelaria apenas que

\footnotetext{
${ }^{12}$ Ryan Hanley menciona esse parágrafo com o intuito de mostrar que Smith teria uma "ética normativa" cuja tarefa principal seria proporcionar recursos aos indivíduos para "superar a própria parcialidade [self-partiality] natural e destruir o egocentrismo que deriva dela” (Hanley, 2017, p. I06).
} 
"preferências sociais" (para utilizar o termo de Samuel Bowles para se referir aos motivos que levam as pessoas ajudarem umas às outras ${ }^{13}$ ) têm papel secundário na promoçáo da coesão. Similarmente, o "negativismo" da justiça — justiça que viabiliza a busca de cada ator comercial por satisfazer seus desejos sem terem interferências em seus negócios - produz a negligência ou o "esvaziamento" (crowding-out) do serviço público, e a corrosão do cimento social.

Um browniano poderia levar suas críticas ainda mais longe. Preferências sociais não são secundárias, são essenciais. A exemplo da crítica de Hume ao contratualismo ou do argumento posterior de Herbert Hart (I96I, p. 219-220), a obrigação que um açougueiro tem de fornecer o número correto de salsichas aos clientes pressupóe alguma regra de conduta pré-existente, a qual não pode estar ancorada na obrigação de seguir regras - afinal, não faz sentido fazer uma promessa para manter promessas. Implicitamente, Smith responde que os indivíduos vão, de fato, além do cumprimento das regras de justiça ao reverenciá-las. Chega a reiterar que sem tal reverência ou um "respeito sagrado" (sacred regard) pelas regras, a sociedade humana "desmoronaria, tornando-se um nada", pois não poderia contar com a reciprocidade das ações humanas (TMS, III.5.2, p. I63) ${ }^{14}$.

Qual a origem dessa reverência? A resposta de Smith é conhecida: ela é efeito do hábito, "da observação contínua" de condutas alheias que internalizamos (TMS, III.4.7, p. I59; III.5.2, p. I63). Acredito que Smith considere isso robusto o suficiente, enquanto, presumivelmente, Brown não. $\mathrm{O}$ último defenderia, nos termos de Smith, que "as regras da moralidade importantes são os comandos e as leis de Deus". Essa afirmação é explicitamente classificada por Smith como "opinião" 15 , que aprimora a "reverência habitual", mas que, ao meu ver, não pode ser a origem da própria reverência. Tal opiniáo, entretanto, tem origem na "natureza", isto é, na natureza humana, sendo característica da "ignorância e [da] obscuridade da superstição pagã" (TMS, III.5.4, p. I64), por mais que depois seja confirmada por "investigaçóes filosóficas”. O que é confirmado, eu sugeriria, é a própria opinião de que os seres humanos esperam de modo ubíquo a recompensa pela obediência às leis divinas e a

\footnotetext{
${ }^{13}$ Bowles, 2016, p. 45, cf. p. 76 .

${ }^{14}$ A importância da "reverência" é destacada por Charles Griswold (I999, p. 237). Ver também sua obra JeanJacques Rousseau and Adam Smith (2017, p. 242), onde refere-se ao "espaço afetivo", estabelecido pelo senso de justiça junto de "instituiçóes mediadoras" e da simpatia pela própria comunidade, espaço em que o "respeito sagrado" pode estar localizado. Samuel Fleischacker julga que a referência ao sagrado corresponde à "inspiração" ("awe-inspiring"), sendo ela central para o funcionamento das regras (Fleischacker, 2004, p. 7I).

${ }^{15} \mathrm{O}$ emprego do termo "opinião" por Smith nesse caso não é técnico, mas muito próximo do nosso uso contemporâneo para se referir a uma visão em particular, inclusive a nossa própria e a de demais pessoas. No presente contexto, alguns parágrafos depois, Smith reafirma que é uma opiniáo pensar que o Autor da natureza tem em mente a felicidade dos seres humanos, mas não chega a dizer se a verdade sobre isso é confirmada pelo "exame da obra da natureza" (TMS, III.5.7, p. I66).
} 
punição pela desobediência em alguma vida por vir (cf. TMS, II.ii.3.I2, p. 9I, III.2.33, p. I32).

Encaminhamo-nos assim para a conclusão. Na Teoria dos Sentimentos Morais, Smith distingue concordância de unissonância (TMS, I.i.4.7, p. 22). Enquanto concordância é uma negociação entre atores e espectadores refletida pelo espelho social que produz "harmonia", isto é, coesão social, a unissonância não é diferençável. A sociedade comercial smithiana é baseada na concordância, enquanto a sociedade contemplada ou defendida por Brown é fundamentada na unissonância, no sentido de incorporar uma uniformidade. Ora, esta última não é moralmente atraente, pois contraria os princípios da liberdade natural, segundo os quais indivíduos devem ser deixados completamente livres para seguirem seus interesses próprios como preferirem desde que as leis da justiça não sejam violadas (WN, IV.ix.5I, p. 687). Como Smith afirma, sintomaticamente, acerca da legislação sumptuária, seria uma "impertinência aberrante" que o governo determinasse as roupas que devo vestir (WN, II.iii.36, p. 346). Contudo, essa legislaçáo sintetiza o que a unissonância corresponderia na prática.

Portanto, a concordância produzida na sociedade comercial é, para Smith, mais robusta que uma "corda de areia". Essa força ou resiliência não é fatalmente dissipada pela presença de aspectos negativos na sociedade comercial, como o crescimento da dívida ou o embrutecimento da força de trabalho. A presença do interesse próprio, juntamente com suas consequências — ou seja, o que Brown enxerga como fraqueza - é a força da sociedade comercial, pois se trata, afinal, de um princípio constante e universal da natureza humana.

Mas o apelo à noção de natureza humana não é uma resposta definitiva. Para ilustrar isso, retorno à objeção browniana de que a sociedade de trocas é fruto de contingências, objeção que reaparece em Marx. Em seus escritos de I843-I844, especialmente nos comentários sobre James Mill, Marx vale-se da necessidade como princípio da verdadeira natureza humana comunal (communal) e julga deficiente o modelo de trocas smithiano. Na leitura de Marx, Adão e Eva veem suas facas e garfos como objetificação de seus interesses próprios, e não como expressão consumada da produtividade humana. Caso Eva possua apenas uma faca e Adão tenha uma faca e dois garfos, ela se verá impotente, e terá de implorar ao outro, pois não terá nada a oferecer pelo garfo (Marx, 1975) ${ }^{16}$, tal como o pedinte diante do açougueiro. Para Marx, na ausência de propriedade privada, a carência de um garfo da parte de Eva seria suprida por Adão, e isso porque seria considerada por ele como um ser

\footnotetext{
${ }^{16}$ Eu discuto o argumento de Marx (mobilizando o mesmo exemplo) em Berry, 1987.
} 
humano. Mas a versão de Marx parece implicar unissonância, já que a expressão da natureza humana (ou a "essência da espécie", Gattungwesen) tem de ser necessariamente a mesma em todos os indivíduos ${ }^{17}$.

\section{VI}

É uma questão saber se teríamos como escolher entre diferentes concepçóes da natureza humana; não é, porém, a minha tarefa examinar essa questão ${ }^{18}$. Em vez disso, concluirei reiterando dois pontos. Em primeiro lugar, de acordo com sua concepção de natureza humana, Smith atribui à sociedade comercial o estabelecimento da concordância em grau suficiente para conformar uma "harmonia social" (WN, I.i.4.7, p. 22). Mostra que a sociedade fundada na concordância não é apenas viável, mas moralmente superior àquela baseada na unissonância. Logo, a nostalgia de Brown por um período anterior é equivocada. Em segundo lugar, conforme esse mesmo raciocínio, a crítica de Brown é, ainda mais por sua veemência, mal direcionada e injustificada. A sociedade comercial é robusta, e sua coesão é mais forte que uma "corda de areia"; ou, se quisermos evocar aqui outra expressão célebre, diríamos que a sua sustentação está mais para a de um "bloco de granito" (a lump of granite).

\section{Referências bibliográficas}

Berry, J. C. (2013). The idea of a Commercial Society in the Scottish Enlightenment. Edinburgh: Edinburgh University Press.

Berry, J. C. (1987). "Need and Egoism in Marx's Early Writings", History of Political Thought, VII, pp. 46I-473.

Berry, J. C. (1986). Human Nature. Londres: Macmillan.

Bowles, S. (2016). The Moral Economy. New Haven: Yale University Press.

Brown, J. (1757). An Estimate of the Manners and Principles of the Times. Londres.

Ferguson, A. (1966). An essay on the History of Civil Society [1767]. D. Forbes (ed.). Edinburgh: Edinburgh University Press.

Ferguson, A. (2019) Ensaio sobre a história da sociedade civil. Trad. Pedro Paulo Pimenta e Eveline Campos Hauck. São Paulo: Editora Unesp.

Fleischacker, S. (2004). On Adam Smith's Wealth of Nations. Princeton: Princeton University Press.

Griswold, C. (1999). Adam Smith and the Virtues of Enlightenment. Cambridge: Cambridge University

\footnotetext{
${ }^{17}$ Ver seu comentário Marx, I982, IV vol. 2, p. 465 (cf. Id., 1975, p. 277-278).

${ }^{18}$ Para uma discussão sobre esse ponto, ver Berry, i986, capítulo Io.
} 
Griswold, C. (2017). Jean-Jacques Rousseau and Adam Smith. Londres: Routledge. Hanley, R. (2009). Adam Smith and the Character of Virtue. Cambridge: Cambridge University.

Hanley, R. (2017). Love's Enlightenment. Cambridge: Cambridge University Press. Hart, H. L. A. (196r). The Concept of Law. Oxford: Clarendon Press.

Hobbes, T. (1991). Leviathan [165I]. R. Tuck (ed.). Cambridge: Cambridge University Press.

Hume, D. (1932). The letters of David Hume (2 vols). Greig, J. (ed.). Oxford: Claredon Press.

Hume, D. (1987a). A Treatise of Human Nature [1739/1740]. L. Selby-Bigge e P. Nidditch (ed.). Oxford: Claredon Press.

Hume, D. (1987b). Essays: Moral, Political and Literacy [174I]. E. Miller (ed.). Indianapolis, Liberty Press.

Hume, D. (1998). An Inquiry concerning the Principles of Morals [I75I]. T. Beauchamp (ed.). Oxford: Oxford University Press.

Hutcheson, F. (1994). Philosophical Writings. R. Downie (ed.). Londres: Everyman.

Mandeville, B. (1998). The Fable of the bees [1732]. F. Kaye (ed.). 2 vols. Indianapolis: Liberty Press.

Marx, K. (1975). “Excerpts from James Mill”. In: Marx, K. Early Writings. L. Colletti (ed.). Harmondsworh: Penguin Books, pp. 259-278.

Marx, K. (I982). "Aus James Mill”. In: Marx, K; Engels, F. K. Marx and F. Engels Gesamtausgabe. Berlin: Dietz Verlag.

Millar, J. (2000). An Historical View of the English Government. M. Salber Phillips e D. Smith (ed.). Indianapolis: Liberty Press.

Ostrom, E. (1998). "A Behavioral Approach to the Rational Choice of Collective Action", American Political Science Review, 99, pp. I-22.

Shaftesbury, A. C. $3^{\text {rd }}$ Lord of. (1990). Characteristics of Men, Manners, Opinions, Times etc. J. Robertson (ed.). 2 vols. Londres: Grant Richards.

[WN] Smith, A. (198I). An Inquiry into the Nature and Causes of the Wealth of Nations. Glasgow Edition. R. Campbell e A. Skinner (ed.). Indianapolis: Liberty Fund, I98I

[TMS] Smith, A. (1982). The Theory of Moral Sentiments [1757/90]. Glasgow Edition. A. Macfie e D. Raphael (ed.). Indianapolis: Liberty Press, I982.

Smith, A. (1982). Lectures in Jurisprudence. Glasgow Edition. R. Meek, D. Raphael e P. Stein (ed.). Indianapolis: Liberty Press.

Smith, A. (1983). Lectures on Rhetoric and Belles Lettres. Glasgow Edition. J. Bryce (ed.). Indianapolis: Liberty Press.

Wallace, R. (1768). Characteristics of the Present Political State of Great Britain. Londres, $2^{\mathrm{a}}$ edição. 